\title{
High particulate matter emission from additive-free Natural American Spirit cigarettes
}

Yvonne Iffland* ${ }^{*}$, Ruth Müller, David Groneberg and Alexander Gerber

\begin{abstract}
Background: Involuntary exposure to health-threatening environmental tobacco smoke (Combined Mainstream and Side-stream Smoke, CMSS) is a worldwide problem, causing premature death of thousands of people. CMSS consists of particulate matter (PM), one of the main sources of indoor air pollution. PM constitutes a considerable health risk for passive smokers. It is important to inform the public about brand-specific differences in CMSSassociated PM, especially in the case of brands without additives, which are therefore promoted as natural and less health-threatening.
\end{abstract}

Methods: Mean concentrations and the area under the curve of $\mathrm{PM}_{10}, \mathrm{PM}_{2.5}$ and $\mathrm{PM}_{1}$ generated by Natural American Spirit cigarettes without additives and the 3R4F standard research cigarette (University of Kentucky, USA) were measured, analyzed and compared with each other. An automatic environmental tobacco smoke emitter was used to smoke 100 cigarettes, 20 of each brand, according to a standardized smoking protocol.

Results: This study could show that CMSS-associated PM released from tobacco brands without additives, which are therefore promoted as natural and less harmful, are higher than expected

Conclusions: It is highly improbable that Natural American Spirit tobacco products are a less harmful choice —at least not for passive smokers as this study could show. We conclude, the CMSS-associated PM level of every single customized brand should be measured because the origin of the tobacco and not the amount of CO, tar and nicotine (given as product information) seem to be responsible for the brand-specific PM release. This data is urgently needed to adequately inform the public about CMSS-associated PM exposure and the related health risk especially for passive smokers.

Keywords: Particulate matter, Indoor air pollution, Cigarettes

\section{Background}

Air pollution and its health hazards have been an important issue for researchers for decades. Besides other noxious components, airborne particulate matter (PM) contributes to ambient air pollution. PM consists of solid and liquid droplets floating through the air and can be inhaled by our lungs. The U.S. Environmental Protection Agency (EPA) distinguishes $\mathbf{P M}_{\mathbf{1 0}}$ or coarse particles with a diameter of 2.5-10 $\mu \mathrm{m}$ and $\mathbf{P M}_{2.5}$ or fine particles with a

\footnotetext{
*Correspondence: yvonne.iffland@googlemail.com Center for Health Sciences, Institute of Occupational, Public and Environmental Medicine, Goethe University Frankfurt am Main, Frankfurt am Main, Germany
}

diameter of $2.5 \mu \mathrm{m}$ or less. ${ }^{1} \mathrm{PM}_{1}$ defines ultrafine particles with a size of less than $1 \mu \mathrm{m} .{ }^{2}$ PM originates either from natural sources such as fire, volcano eruption or pollen or from human activities such as cooking, heating, industries, traffic or smoking (see footnote 1). After being inhaled PM causes severe consequences on human health in a dose-response manner, which has been demonstrated in several studies (Choudhury et al. 1997; Laden

\footnotetext{
${ }^{1}$ EPA US, OAR, OAQPS. Particulate Matter | Air \& Radiation | US EPA 10.09.2015. http://www3.epa.gov/pm/. Accessed 19 Jan 2016.

2 Green Facts. Air Pollution Particulate Matter. http://www.greenfacts.org/ en/particulate-matter-pm/level-2/01-presentation.htm. Accessed 16 Feb 2016.
}

\section{Springer Open}


et al. 2006; Atkinson et al 2001; Bell et al. 2008; Brook et al 2010). Furthermore the toxicity of PM is size-depending. The smaller the diameter of the particles, the deeper they can reach into our respiratory system (Li et al. 2016). Particles with a size of less than $2.5 \mu \mathrm{m}$ are even able to reach the alveoli, the gas exchange regions, where they might also be transferred to the bloodstream (Siponen et al. 2015). PM exposure is associated with e.g. cardiovascular, respiratory tract diseases, sudden infant death syndrome (SIDS), preterm birth and premature death (Bell et al. 2008; Jacquemin et al. 2015; Qiu et al. 2014; U.S. Department of Health and Human Services 1986; Lai et al. 2016).

PM levels can sometimes be higher in enclosed buildings than outdoors because PM concentrations are less diluted indoors (Umweltbundesamt 2014). People spend almost $87 \%$ of their daily lives inside (Klepeis et al. 2001). More than 50\% of England's households have at least one smoker. In some of these households smoking takes place in the presence of children (Albar et al. 2014). These findings also match for Germany (Brenner and Mielck 1993).

Combined Mainstream and Sidestream Smoke (CMSS) exposure causes death of 41,000 American adult nonsmokers every year (King et al. 2014). Studies suggest that besides various other noxious substances in CMSS, PM itself is a health-threatening component of CMSS, leading to increased illness and deaths (Atkinson et al 2001; Bell et al. 2008; Brook et al. 2010; Sunyer and Basagaña 2001). Taking into account that the majority of people spend their time indoors, and many are involuntarily exposed to CMSS, we find it extremely relevant to investigate PM levels that occur by smoking inside. Moreover, we believe it is crucial to provide consumers with information not only about nicotine-, tar- and CO-content of their cigarette, but about the amount of PM that is released by it, as it presents a risk factor on its own.

The ToPIQ-II study tends to investigate brand-specific differences in the amount of PM emission of different tobacco products. Natural American Spirit cigarettes, produced by Santa Fe Natural Tobacco Company, are promoted to be additive-free and thus supposed to be natural and healthy tobacco products. The company targets "socially and environmentally conscious smokers" who want to stand out of the crowd (McDaniel and Malone 2007). Consumers believe in this promising advertisement and tobacco products, such as Natural American Spirit cigarettes, are gaining popularity (McDaniel and Malone 2007). ${ }^{3,4,5}$ In this trial, PM emissions of Natural American

\footnotetext{
${ }^{3}$ Fay JE. "All Natural" concept evaluation. https://industrydocuments.library. ucsf.edu/tobacco/docs/\#id=yrcx0084. Accessed 21 Jan 2016.

${ }^{4}$ Gurry N. All natural concept product test. https://industrydocuments. library.ucsf.edu/tobacco/docs/\#id=nkkl0106. Accessed 21 Jan 2016.

5 Farrell B. The "Green" Cigarette? http://www.plentymag.com/features/2008/12/the_green_cigarette_print.php. Accessed 21 Jan 2016.
}

Spirit cigarettes without additives were generated and then the CMSS exposure risk for passive smokers was analyzed.

\section{Methods \\ Tobacco products}

The four tobacco products, tested in present study, belong to the brand Natural American Spirit cigarettes, produced by Santa Fe Natural Tobacco Company. Natural American Spirit orange contained $0.4 \mathrm{mg}$ nicotine, $3 \mathrm{mg}$ tar and $4 \mathrm{mg} \mathrm{CO}$ per cigarette. The blue counterpart had a nicotine yield of $1 \mathrm{mg}$, a tar yield of $9 \mathrm{mg}$ and a $\mathrm{CO}$ yield of $10 \mathrm{mg}$. The green type contained $0.8 \mathrm{mg}$ nicotine, $7 \mathrm{mg}$ tar and $8 \mathrm{mg} \mathrm{CO}$ and the yellow type, respectively, 0.6, 5 and $6 \mathrm{mg}$. ${ }^{6}$ These tobacco products were analyzed and compared with 3R4F standard research cigarettes, ${ }^{7}$ which have a nicotine content of $0.726 \mathrm{mg}$, a tar yield of $9.4 \mathrm{mg}$ and a CO content of $11.9 \mathrm{mg}$. Reference cigarettes have been used in scientific studies for several years, e.g. in order to analyze their chemical or toxicological effects in comparison to commercial tobacco products. ${ }^{8}$

\section{Automatic environmental tobacco smoke emitter (AETSE)}

This experiment is part of the ToPIQ-II study and therefore has the same setup as previously conducted studies (Wasel et al. 2015; Gerber et al. 2015a, b; Mueller et al. 2012). Developed and constructed by Schimpf-Ing, Trondheim Norway, the AETSE was placed in a $2.88 \mathrm{~m}^{3}$ glass chamber that serves as a defined indoor space. The AETSE was equipped with a $200 \mathrm{ml}$ glass syringe, a microcontroller, a stepper motor, aluminum profiles, a dilution system and other mechanical devices. The originated PM levels were diluted in a ratio of 1:10 by the dilution system before being analyzed. Actual values are, respectively, ten times higher.

The glass syringe generated puffs of $40 \mathrm{ml}$ volume through pushing and pulling. The stepper motor made it possible to evoke the automatic pushes and pulls of the syringe plunger. By pulling the syringe, inhalation was simulated. Correspondingly, by pushing the syringe, the inhaled CMSS was exhaled into the glass chamber through the hose system. Particularly, this procedure imitated the mainstream smoke. Between two puffs, the smoldering cigarette steadily produced side-stream smoke (SS) which together with mainstream smoke added up to

\footnotetext{
${ }^{6}$ Santa Fe Natural Tobacco Company. Natural American Spirit ${ }^{\circledR}$ | SFNTC. https://www.naturalamericanspirit.de/. Accessed 20 Jan 2016.

7 University of Kentucky. CTRP - Center for Tobacco Reference Products. 16.01.2016. https://refcig.uky.edu/client/index.html. Accessed 20 Jan 2016.

8 Reference products used in tobaccoand smoke analyses. Tobacco Journal International 2013
} 
CMSS that was measured constantly, every $6 \mathrm{~s}$, by a laser aerosol spectrometer (Model 1.109, Grimm Co., Ainring, Germany). Placed in a separate room, the glass chamber was equipped with rubber gloves. Using these gloves smoking cycles were started and finished from the outside of the chamber without opening the chamber's door so that the examiner was not exposed to CMSS at any time. Additionally, turbulences and ventilations in the chamber by opening the door could be minimized.

\section{Smoking protocol}

In order to smoke cigarettes in a standardized, reproducible and reliable way, the following four-phase smoking protocol was used: (1) the pre-igniting phase, (2) the combustion phase, (3) the post-combustion phase and (4) the suction phase (Fig. 1).

The pre-igniting phase lasted $5 \mathrm{~min}$. During this time pre-PM levels in the glass chamber are measured in order to receive baseline PM levels. After the 5 min a cigarette is manually lit by the examiner from the outside of the glass chamber using the provided gloves. In the combustion phase the cigarette is smoked until $0.5 \mathrm{~cm}$ remain to the filter. Natural American Spirit cigarettes needed 13 puffs, each lasting $3 \mathrm{~s}$. 3R4F needed 8 puffs with the same duration. This results in a combustion time of $7 \mathrm{~min}$ and $35 \mathrm{~s}$ for Natural American Spirit cigarettes and $4 \mathrm{~min}$ and $55 \mathrm{~s}$ for 3R4F. The volume of each puff is $40 \mathrm{ml}$ and the time in-between two puffs is $24 \mathrm{~s}$. The first puff needed to be a double puff to avoid the extinguishing of the cigarette. At the end of this phase the cigarette was manually extinguished in a bowl filled with water. Subsequently, the 5-min post-combustion phase began. Afterwards a 5-min suction phase followed in order to clean the air in the glass chamber for the next cycle.

\section{Data processing and analysis}

Each smoking cycle was analyzed for the area under the curve (AUC) and the mean concentration $\left(\mathrm{C}_{\text {mean }}\right)$ of $\mathrm{PM}_{10}, \mathrm{PM}_{2.5}$ and $\mathrm{PM}_{1}$, using the tenfold values detected by the laser aerosol spectrometer. To estimate the reliability of single measurements, the percentage AUC of all peaks greater than threefold of the CMSS measured during the post-combustion phase was calculated in five randomly selected cigarettes per brand. A percentage greater than $22 \%$ was set as an internal limit, indicating that the impact of mainstream smoke is too high. Among the 20 cigarettes per PM class and product, outliers were identified with the Iglewicz and Hoaglin's robust test for multiple outliers (one outlier for Natural American Spirit orange could be detected and then excluded from the results). Subsequently, Gaussian normality of the AUC and $\mathrm{C}_{\text {mean }}$ per PM class and tobacco product was tested, applying the D'Agostino-Pearson test and a significance level of 0.05. Additionally, log-transformed AUC and $\mathrm{C}_{\text {mean }}$ of $\mathrm{PM}_{10}, \mathrm{PM}_{2.5}$ and $\mathrm{PM}_{1}$ with homogeneous variances (Bartlett's test, $\mathrm{p}=0.18$ ) were tested for significant differences between the five tobacco products, using oneway ANOVA and Tukey posthoc tests. This statistical method was also applied to examine the influence of the combustion time in reference to the PM emission. Using the Spearman correlation test, physiological factors such as $\mathrm{CO}$, nicotine and tar content were examined in respect to their influence on PM emission. All statistics were computed with the software Graph Pad Prism version 6.

\section{R4F}

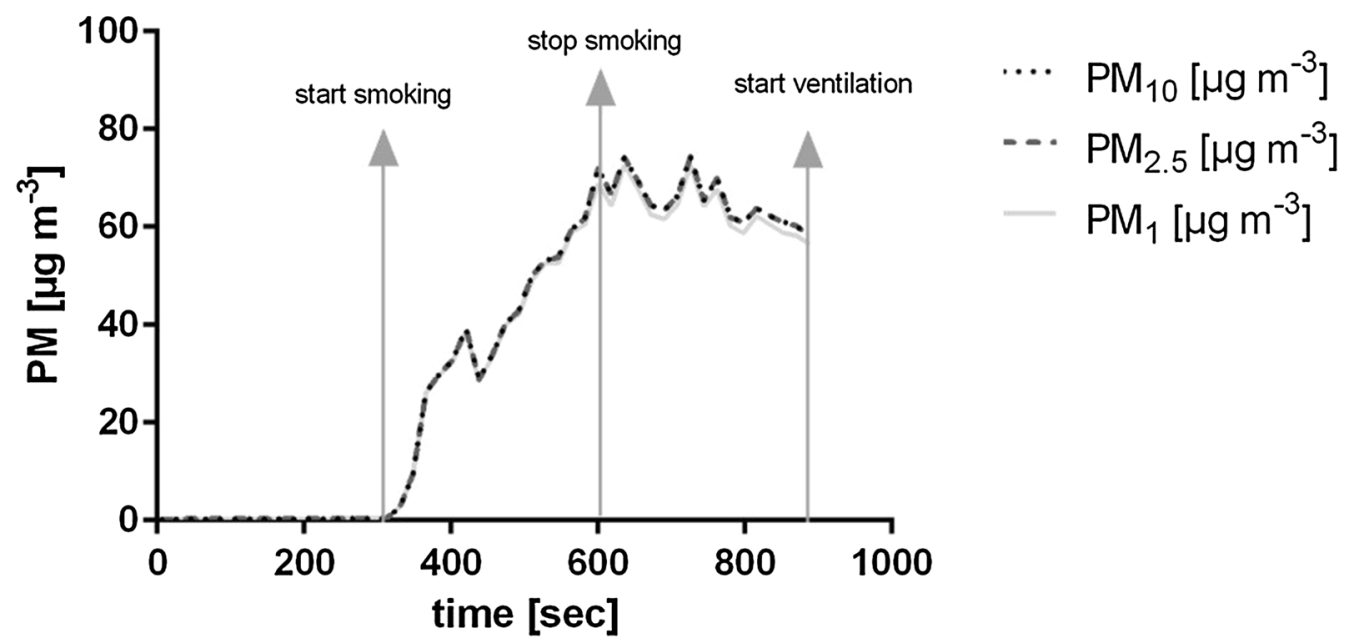

Fig. 1 Sample measuring cycle 


\section{Results}

The proportion of artificial peaks was highest for Natural American Spirit yellow with 14.6\% (3R4F: $8.2 \%$; orange: $4.6 \%$; blue: $7.6 \%$; green: $6.6 \%$ ), but smaller than $22 \%$. Thus it can be assumed that mainly SS was measured. A Gaussian distribution could be found for all PM values of each tested cigarette brand $(\mathrm{p} 3 \mathrm{R} 4 \mathrm{~F}=0.46$; $\mathrm{p}$ orange $=0.08 ; \mathrm{p}$ blue $=0.69 ;$ preen $=0.27$; yellow $=0.41) . \mathrm{C}_{\text {mean }}$ of $\mathrm{PM}_{10}$ and the AUC-PM 10 of Natural American spirit orange are 1.3 times higher than $\mathrm{C}_{\text {mean }}$ of the blue type, 1.9 times higher than $\mathrm{C}_{\text {mean }}$ of the green type and 1.8 times higher than $\mathrm{C}_{\text {mean }}$ of the yellow type (Fig. 2; Table 1). The same relation between tobacco products applies for the $C_{\text {mean }}$ of $\mathrm{PM}_{2.5}$ and $\mathrm{PM}_{1}$ and the AUC-PM ${ }_{2.5}$ and AUC-PM . AUC levels of Natural American Spirit cigarettes are significantly higher than those of 3R4F, which is probably caused by the longer time of combustion. Whereas 3R4F cigarettes only needed 8 puffs, respectively, a combustion time of 4:55 min, all Natural American Spirit cigarettes burned 7:35 min (13 puffs). The relation between combustion time and CMSS emission was significant ( $\mathrm{p}<0.001)$. A specific scattering scheme for each cigarette could be detected (Table 2; Fig. 3). PM emission of Natural American Spirit orange mainly consists of $\mathrm{PM}_{1}$ $\left(97.66 \mu \mathrm{g} \mathrm{m}^{-3}=92.4 \%\right)$, only $7.6 \%\left(8.04 \mu \mathrm{g} \mathrm{m}^{-3}\right)$ of $\mathrm{PM}_{2.5}$ and $0.02 \%\left(0.02 \mu \mathrm{g} \mathrm{m}^{-3}\right)$ of $\mathrm{PM}_{10}$. PM concentrations of Natural American Spirit blue are divided into 92\% $\left(73.55 \mu \mathrm{g} \mathrm{m}^{-3}\right) \mathrm{PM}_{1}, 7.4 \%\left(5.9 \mu \mathrm{g} \mathrm{m}^{-3}\right) \mathrm{PM}_{2.5}$ and $0.6 \%$ $\left(0.14 \mu \mathrm{g} \mathrm{m}^{-3}\right) \mathrm{PM}_{10}$. PM emitted by Natural American Spirit green is also mainly composed by $\mathrm{PM}_{1}$ with $94.8 \%$ $\left(53.18 \mu \mathrm{g} \mathrm{m}^{-3}\right)$, and the remaining parts are distributed to $\mathrm{PM}_{2.5}$ with $5.1 \%\left(2.79 \mu \mathrm{g} \mathrm{m}^{-3}\right)$ and $\mathrm{PM}_{1}$ with $0.1 \%$ $\left(0.06 \mu \mathrm{g} \mathrm{m}^{-3}\right)$. The distribution pattern is similar for Natural American Spirit yellow: $\mathrm{PM}_{1}$ 95.1\% $\left(53.18 \mu \mathrm{g} \mathrm{m}^{-3}\right)$, $\mathrm{PM}_{2.5} 4.8 \%\left(2.7 \mu \mathrm{g} \mathrm{m}^{-3}\right)$ and $\mathrm{PM}_{10} 0.01 \%\left(0.04 \mu \mathrm{g} \mathrm{m}^{-3}\right)$.

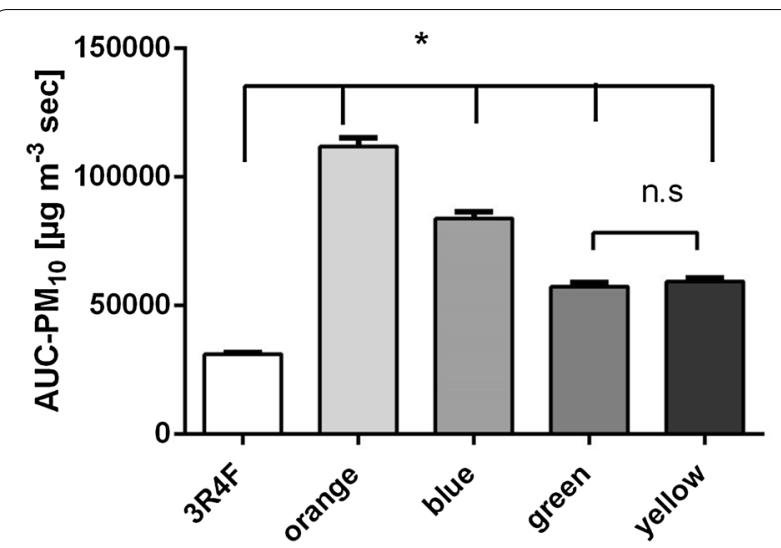

Fig. 2 Comparison of the AUC of 3R4F and Natural American Spirit cigarettes (significance was assumed when $p<0.05$; ${ }^{*}$ significant, $n s$ non-significant
Taking the varying CMSS-associated PM amounts of different Natural American tobacco products into account, the question arises which factors do have an influence on the CMSS emissions, remembering that Natural American Spirit cigarettes are supposed to be free of additives (see footnote 6). Therefore correlations between nicotine-, tar- and CO-content and filling density were performed. Neither a correlation between nicotine-, tar- and CO-content and PM values nor filling density or tobacco weight and PM emission could be found ( $r=-0.04$ for all correlations).

\section{Discussion}

We were successful to demonstrate significant brandspecific differences regarding PM concentrations in CMSS. CMSS emissions are not predictable by CO-, tar- and nicotine-content, given as product information. They appear to depend on the origin of the tobacco and the brand-specific design of the tobacco product and its typical tobacco blend. This result implies that standardized brand-specific measures of CMSS emissions are inevitable for exposure risk assessment, especially when compared to a standard reference cigarette, and should be stated as product information on tobacco products.

\section{Brand-specific PM differences}

Additive-free cigarettes, typically promoted as natural tobacco products, do not decrease the CMSS exposure risk for passive smokers. We state that CMSS emission is high and CMSS consists mainly of particles with a size of $0.1-1 \mu \mathrm{m}$ (>90\%). A possible explanation may be the impact of the tobacco, used in these cigarettes. If the tobacco differs, for example, in the amount of cellulose or contains different phytochemicals, this might have an effect on combustion. Wasel et al. (2015) examined PM emission released by L\&M cigarettes with and without additives. Also in this trial $\mathrm{C}_{\text {mean }}$ of $\mathrm{PM}_{2.5}$ of the additive-free product were higher $\left(576 \mu \mathrm{g} \mathrm{m} \mathrm{m}^{-3}\right)$ when compared with the types containing additives (LM blue: $448 \mu \mathrm{g} \mathrm{m}^{-3}$; LM red: $547 \mu \mathrm{g} \mathrm{m}^{-3}$ ). Besides the higher PM emissions, additive-free Natural American Spirit tobacco products also reveal a potential health risk on passive smokers because of the distribution pattern of emitted fine particles. By far the highest part of PM in SS consists of $\mathrm{PM}_{1}$, which is most threatening on human health ( $\mathrm{Li}$ et al. 2016). After extended research we believe that other than in the ToPIQ-II (Wasel et al. 2015; Gerber et al. 2015a, b; Mueller et al. 2012), differences between brands regarding PM emission in SS have not been investigated. Nevertheless, there are a few studies where CMSS-associated PM concentrations were measured. However, in those cases CMSS was not automatically generated by a 
Table 1 Overview of AUC and $C_{\text {mean }}$ of all investigated cigarettes and their combustion time

\begin{tabular}{|c|c|c|c|c|c|c|c|}
\hline \multirow{2}{*}{$\begin{array}{l}\text { Tobacco } \\
\text { product }\end{array}$} & \multicolumn{2}{|l|}{$\mathrm{PM}_{10}$} & \multicolumn{2}{|l|}{$\mathrm{PM}_{2.5}$} & \multicolumn{2}{|l|}{$\mathrm{PM}_{1}$} & \multirow{2}{*}{$\begin{array}{l}\text { Time } \\
\text { of combus- } \\
\text { tion } \\
\text { Sec }\end{array}$} \\
\hline & $\begin{array}{l}\operatorname{AUC~PM}_{10} \\
\left(\mu \mathrm{g} \mathrm{m}^{-3} \mathrm{~s}\right) \times 10\end{array}$ & $\begin{array}{l}C_{\text {mean }}{ }^{P M_{10}} \\
\left(\mu \mathrm{g} \mathrm{m}^{-3}\right) \times 10\end{array}$ & $\begin{array}{l}\text { AUC PM } \\
\left(\mu \mathrm{g} \mathrm{m}^{-3} s\right) \times 10\end{array}$ & $\begin{array}{l}C_{\text {mean }} \mathrm{PM}_{2.5} \\
\left(\mu \mathrm{g} \mathrm{m}^{-3}\right) \times 10\end{array}$ & $\begin{array}{l}\mathrm{AUC} \mathrm{PM}_{1} \\
\left(\mu \mathrm{g} \mathrm{m}^{-3} \mathrm{~s}\right) \times_{10}\end{array}$ & $\begin{array}{l}C_{\text {mean }} \mathrm{PM}_{1} \\
\left(\mu \mathrm{g} \mathrm{m}^{-3}\right) \times 10\end{array}$ & \\
\hline $3 R 4 F$ & $30,952 \pm 1420$ & $34.59 \pm 2.01$ & $30,943 \pm 2356$ & $34.58 \pm 2.01$ & $30,051 \pm 2513$ & $33.61 \pm 2.62$ & 295 \\
\hline Orange & $111,494 \pm 15,503$ & $105.9 \pm 7.21$ & $111,276 \pm 15,390$ & $105.7 \pm 7.82$ & $100,729 \pm 11,201$ & $93.17 \pm 7.37$ & 455 \\
\hline Blue & $83,681 \pm 12,257$ & $79.59 \pm 7.47$ & $83,533 \pm 11,696$ & $79.45 \pm 7.47$ & $78,720 \pm 6216$ & $71.83 \pm 11.67$ & 455 \\
\hline Green & $57,183 \pm 5658$ & $54.37 \pm 4.19$ & $57,115 \pm 5658$ & $54.31 \pm 5.59$ & $53,324 \pm 4192$ & $52.69 \pm 5.47$ & 455 \\
\hline Yellow & $59,178 \pm 7615$ & $55.92 \pm 6.26$ & $59,133 \pm 7615$ & $55.88 \pm 1.28$ & $56,141 \pm 5914$ & $54.17 \pm 2.17$ & 455 \\
\hline
\end{tabular}

Table 2 Distribution pattern of PM emissions

\begin{tabular}{|c|c|c|c|c|c|}
\hline 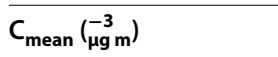 & $3 R 4 F$ & Orange & Blue & Green & Yellow \\
\hline $0.25 \mu \mathrm{m}<\mathrm{PM}<10 \mu \mathrm{m}$ & $34.59 \pm 0.65$ & $105.9 \pm 3.39$ & $79.59 \pm 2.50$ & $54.37 \pm 1.59$ & $55.92 \pm 1.28$ \\
\hline $0.25 \mu \mathrm{m}<\mathrm{PM}<2.5 \mu \mathrm{m}$ & $34.58 \pm 0.65$ & $105.7 \pm 3.37$ & $79.45 \pm 2.50$ & $54.31 \pm 1.58$ & $55.88 \pm 1.28$ \\
\hline $0.25 \mu \mathrm{m}<\mathrm{PM}<1 \mu \mathrm{m}$ & $33.47 \pm 0.62$ & $97.66 \pm 2.66$ & $73.55 \pm 2.08$ & $51.52 \pm 1.41$ & $53.18 \pm 1.09$ \\
\hline \multicolumn{6}{|c|}{ Actual PM concentrations due to EPA's definition } \\
\hline$P M_{1-E P A}(<1 \mu m)$ & $33.47 \pm 0.62$ & $97.66 \pm 2.66$ & $73.55 \pm 2.08$ & $51.52 \pm 1.41$ & $53.18 \pm 1.09$ \\
\hline $\mathrm{PM}_{2.5-\mathrm{EPA}}(1-2.5 \mu \mathrm{m})$ & $1.11 \pm 0.03$ & $8.04 \pm 0.71$ & $5.9 \pm 0.42$ & $2.79 \pm 0.17$ & $2.7 \pm 0.19$ \\
\hline $\mathrm{PM}_{10-\mathrm{EPA}}(2.5-10 \mu \mathrm{m})$ & $0.01 \pm 0.065$ & $0.02 \pm 0.02$ & 0.14 & 0.060 .01 & 0.04 \\
\hline
\end{tabular}

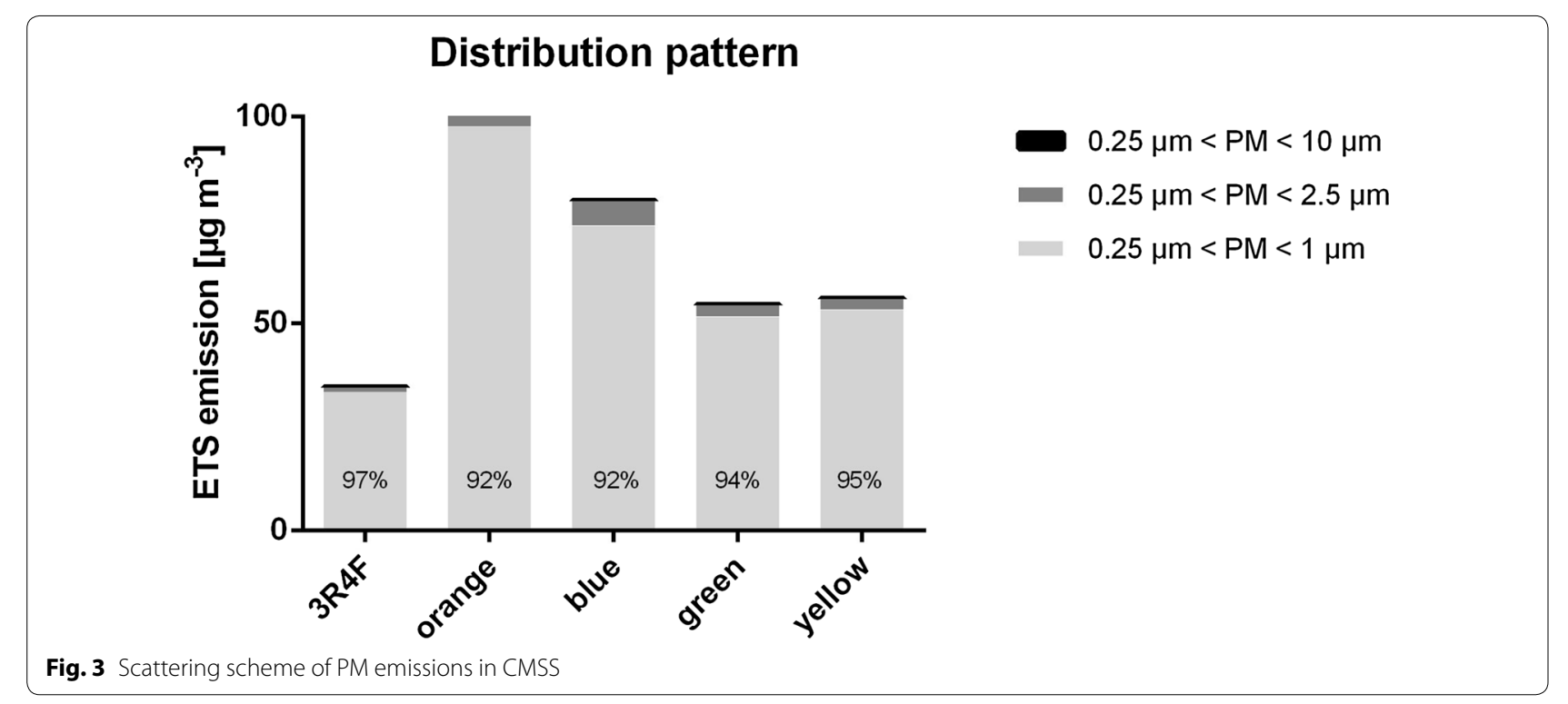

machine but by human smokers (Martin et al. 1997; Nelson et al. 1997; Leaderer and Hammond 1991).

\section{Methodological limitations}

Using the AETSE with a standardized smoking protocol enables us to generate reliable and reproducible PM levels. Nevertheless, it does not imitate the smoking behavior of a real smoker, even if it is possible to alter puff volume, volume flow rate, duration, breaks and repetitions. It is likely that different brands are smoked in different ways, for example due to nicotine, tar and CO content (Guerin 1996; Creighton 1976). If smokers draw longer, mainstream smoke increases. Respectively, if the time between two drags increases, CMSS increases as 
well. However, this method serves the aim to compare PM emission of different brands under the same standardized conditions without exposing humans to harmful CMSS. Before starting the experiments, cigarettes of each type included in the study were smoked until $0.5 \mathrm{~cm}$ remained to the filter. It appears that Natural American Spirit cigarettes needed more drags, in fact 13, to fulfill this criterion, whereas the reference cigarette could be smoked with only eight drags.

We have to admit, that our experiments where not performed with an internationally accepted and recognized smoking regime, such as the "ISO machine smoking regime" or the "Canadian Intense". In fact, our regime is tailor-made and constitutes a mixture of both regimes. We followed the ISO Intense in puff frequency, but reduced the puff volume. This was due to several reasons: First, the technical limitations of our AETSE, which had to be constructed with low financial opportunities, did not allow us to use one of the recognized smoking regimes. Furthermore, most internationally accepted protocols have been heavily criticized (Hammond et al. 2007). Other research groups have reconsidered and modified parameters as well (Baker 2002).

It should be mentioned though, that we were not primarily interested in the absolute amounts of $\mathrm{C}_{\text {mean }}$ and AUC PM $_{2.5}$ of additive free Natural American Spirit cigarettes. All absolute data remain imprecise, as individual smoking behaviors- and conditions vary in countless ways. No smoking protocol is arguably able to exactly imitate human smoking behavior with all its inter- and intra-individual variations in a realistic way. However, the aim of our ToPIQ-II study is to compare different brands and tobacco products with the 3R4F standard research cigarette in terms of their PM emission, when smoked in a standardized way (Gerber et al. 2015a, b). We believe, our protocol is reasonable for this purpose. Nonetheless, we cannot compare our results with finding of other groups, which is admittedly a methodological weakness.

\section{Conclusions}

Besides various additives and the well known toxic and carcinogenic compounds in tobacco products, CMSSassociated PM constitutes an independent health hazard. The smaller the particles are, passive smokers are exposed to, the more deeply they can be inhaled and even penetrate into the blood stream. Depending on their surface and solubility, particles absorb gasses and vapors (e.g. carzinogenic benzopyrenes), permitting their transport in distal lung areas and even to the gas exchanging regions of the Lung. Thus, even if we are not able to conduct a toxicological and chemical analysis of SS with our technical possibilities, it can be assumed that significant differences in PM emissions matter. The release of PM by Natural American Spirit cigarettes was shown to be significantly (2-3 times) higher than that of 3R4F reference cigarettes, when smoked in the same standardize way, using our protocol.

Even if Santa Fe foregoes using additives during the production process of their cigarettes, their tobacco products still evoke high PM emission in SS, which reveals a health hazard to passive smokers. We want to illuminate the impact of these differences on the burden of PM-exposure on passive smokers.

\section{Abbreviations \\ CMSS: Combined Mainstream and Sidestream Smoke; SS: side-stream smoke; AETSE: automatic environmental tobacco smoke emitter; PM: particulate matter; $C_{\text {mean }}$ : mean concentration; AUC: area under the curve; $\mathrm{CO}$ : carbon monoxide; SIDS: sudden infant death syndrome.}

\section{Authors' contributions}

This article is part of the thesis of YI. YI, RM, DAG and AG made substantial contributions to conception and design of the study and acquisition of data, analysis and interpretation of data. YI has conducted the measuring of the cigarettes and has been involved in drafting the manuscript. RM, AG and DAG have been revising it critically for important intellectual content and have given final approval of the version to be published. All authors have participated sufficiently in the work to take public responsibility for appropriate portions of the content and agreed to be accountable for all aspects of the work in ensuring that questions related to the accuracy or integrity of any part of the work are appropriately investigated and resolved. All authors have read and approved the final manuscript.

\section{Acknowledgements}

None.

\section{Competing interests}

The authors declare that they have no competing interests.

\section{Consent of publication}

This article is part of the thesis of YI. YI, AG, DAG and RM have made substantial contributions to the conception and design of the study, acquisition of the data and have been involved in drafting and revising the manuscript. All authors read and approved the final manuscript.

Received: 30 April 2016 Accepted: 2 November 2016

Published online: 11 November 2016

\section{References}

Albar SA, Alwan NA, Evans CEL, Cade JE (2014) Is there an association between food portion size and BMI among British adolescents? Br J Nutr 112:841-851. doi:10.1017/S0007114514001548

Atkinson RW, Anderson HR, Sunyer J, Ayres J, Baccini M, Vonk JM et al (2001) Acute effects of particulate air pollution on respiratory admissions: results from APHEA 2 project. Air Pollution and Health: A European Approach. Am J Respir Crit Care Med 164:1860-1866. doi:10.1164/ajrccm.164.10.2010138

Baker R (2002) The development and significance of standards for smokingmaschine methodology. Contrib Tob Res 20:23-41

Bell ML, Ebisu K, Peng RD, Walker J, Samet JM, Zeger SL, Dominici F (2008) Seasonal and regional short-term effects of fine particles on hospital admissions in 202 US counties, 1999-2005. Am J Epidemiol 168:1301-1310. doi:10.1093/aje/kwn252

Brenner H, Mielck A (1993) Children's exposure to parental smoking in West Germany. http://www.ncbi.nlm.nih.gov/pubmed/8282460. Accessed 20 Jan 2016 
Brook RD, Rajagopalan S, Pope CA, Brook JR, Bhatnagar A, Diez-Roux AV et al (2010) Particulate matter air pollution and cardiovascular disease: an update to the scientific statement from the American Heart Association. Circulation 121:2331-2378. doi:10.1161/CIR.0b013e3181dbece1

Choudhury AH, Gordian ME, Morris SS (1997) Associations between respiratory illness and PM10 air pollution. Arch Environ Health 52:113-117. doi:10.1080/00039899709602873

Creighton DE (1976) Compensation for changed delivery —-truth tobacco industry documents.https://industrydocuments.library.ucsf.edu/tobacco/ docs/\#id=qgkw0200. Accessed 21 Jan 2016

Gerber A, Hofen-Hohloch AV, Schulze J, Groneberg DA (2015a) Tobacco smoke particles and indoor air quality (ToPIQ-II) — a modified study protocol and first results. J Occup Med Toxicol 10:5. doi:10.1186/s12995-015-0047-8

Gerber A, Bigelow A, Schulze M, Groneberg DA (2015b) Brand cigarillos-a cheap and less harmful alternative to cigarettes? Particulate matter emissions suggest otherwise. Int J Environ Res Public Health 12:428-438. doi:10.3390/ijerph120100428

Guerin MR (1996) Sensivity of the federal trade commission test method to analytical parameters

Hammond D, Wiebel F, Kozlowski LT, Borland R, Cummings KM, O'Connor RJ et al (2007) Revising the machine smoking regime for cigarette emissions: implications for tobacco control policy. Tob Control 16:8-14. doi:10.1136/tc.2005.015297

Jacquemin B, Siroux V, Sanchez M, Carsin A, Schikowski T, Adam M et al (2015) Ambient air pollution and adult asthma incidence in six European cohorts (ESCAPE). Environ Health Perspect 123:613-621. doi:10.1289/ ehp. 1408206

King BA, Patel R, Babb SD (2014) Prevalence of smokefree home rules-United States, 1992-1993 and 2010-2011. http://www.ncbi.nlm.nih.gov/pubmed/25188494. Accessed 20 Jan 2016

Klepeis NE, Nelson WC, Ott WR, Robinson JP, Tsang AM, Switzer P, Behar JV, Hern SC, Engelmann WH (2001) The National Human Activity Pattern Survey (NHAPS): a resource for assessing exposure to environmental pollutants. J Expo Anal Environ Epidemiol 11(3):231-252

Laden F, Schwartz J, Speizer FE, Dockery DW (2006) Reduction in fine particulate air pollution and mortality: extended follow-up of the Harvard Six Cities study. Am J Respir Crit Care Med 173:667-672. doi:10.1164/ rccm.200503-4430C

Lai T, Chiang C, Wu C, Yang S, Liu D, Chan C, Lin H (2016) Ambient air pollution and risk of tuberculosis: a cohort study. Occup Environ Med 73:56-61. doi:10.1136/oemed-2015-102995

Leaderer BP, Hammond SK (1991) Evaluation of vapor-phase nicotine and respirable suspended particle mass as markers for environmental tobacco smoke. Environ Sci Technol 25:770-777. doi:10.1021/es00016a023
Li X, Lin B, Zhang H, Xie F, Ta N, Tian L et al (2016) Cytotoxicity and mutagenicity of sidestream cigarette smoke particulate matter of different particle sizes. Environ Sci Pollut Res Int 23:2588-2594. doi:10.1007/ s11356-015-5483-6

Martin P, Heavner DL, Nelson PR, Maiolo KC, Risner CH, Simmons PS et al (1997) Environmental tobacco smoke (ETS): a market cigarette study. Environ Int 23:75-90. doi:10.1016/S0160-4120(96)00079-7

McDaniel PA, Malone RE (2007) "I always thought they were all pure tobacco": American smokers' perceptions of "natural" cigarettes and tobacco industry advertising strategies. Tob Control 16:e7. doi:10.1136/tc.2006.019638

Mueller D, Schulze J, Ackermann H, Klingelhoefer D, Uibel S, Groneberg DA (2012) Particulate matter (PM) 2.5 levels in ETS emissions of a MarIboro Red cigarette in comparison to the $3 \mathrm{R} 4 \mathrm{~F}$ reference cigarette under open- and closed-door condition. J Occup Med Toxicol 7:14. doi:10.1186/1745-6673-7-14

Nelson PR, Conrad FW, Kelly SP, Maiolo KC, Richardson JD, Ogden MW (1997) Composition of environmental tobacco smoke (ETS) from international cigarettes and determination of ETS-RSP: Particulate marker ratios. Environ Int 23:47-52. doi:10.1016/50160-4120(96)00076-1

Qiu J, He X, Cui H, Zhang C, Zhang H, Dang Y et al (2014) Passive smoking and preterm birth in urban China. Am J Epidemiol 180:94-102. doi:10.1093/ aje/kwu092

Siponen T, Yli-Tuomi T, Aurela M, Dufva H, Hillamo R, Hirvonen M et al (2015) Source-specific fine particulate air pollution and systemic inflammation in ischaemic heart disease patients. Occup Environ Med 72:277-283. doi:10.1136/oemed-2014-102240

Sunyer J, Basagaña X (2001) Particles, and not gases, are associated with the risk of death in patients with chronic obstructive pulmonary disease. Int J Epidemiol. 30(5):1138-1140

Umweltbundesamt (2014) Feinstaub in Innenräumen. http://www.umweltbundesamt.de/themen/gesundheit/umwelteinfluesse-auf-den-menschen/innenraumluft/feinstaub-in-innenraeumen. Accessed 20 Jan 2016

U.S. Department of Health and Human Services (1986) A report to the surgeon general. https://profiles.n/m.nih.gov/ps/access/NNBCPM.pdf. Accessed 20 Jan 2016

Wasel J, Boll M, Schulze M, Mueller D, Bundschuh M, Groneberg DA, Gerber A (2015) Brand cigarillos: Low price but high particulate matter levels-is their favorable taxation in the European union justified? Int J Environ Res Public Health. 12(8):9141-9153

\section{Submit your manuscript to a SpringerOpen ${ }^{\circ}$ journal and benefit from:}

- Convenient online submission

- Rigorous peer review

- Immediate publication on acceptance

- Open access: articles freely available online

- High visibility within the field

- Retaining the copyright to your article

Submit your next manuscript at springeropen.com 